\title{
Análisis De Las Variables Físico-Químicas Y Microbiológicas De Las Lagunas Del Municipio De Escárcega, Campeche, México
}

\author{
Blanca del Rosario Martín Canché (Maestra en Gestión y Administración \\ de Proyectos) \\ Maximiliano Vanoye Eligio (Doctor en Ciencias) \\ Martín Gabriel Chan Palomo (Ingeniero bioquímico) \\ José Luis Guillen Taje (Maestro en Gestión Educativa) \\ José de los Ángeles Aguilar Sánchez (Maestro en Administración) \\ Instituto Tecnológico Superior de Escárcega
}

Doi:10.19044/esj.2021.v17n25p116

Submitted: 03 May 2021

Accepted: 21 June 2021

Published: 31 July 2021
Copyright 2021 Author(s)

Under Creative Commons BY-NC-ND 4.0 OPEN ACCESS

Cite As:

Del Rosario Martín Canché B., Vanoye Eligio M., Chan Palom M.G., Guillen Taje J.L \& Ángeles Aguilar Sánchez J. (2021). Análisis De Las Variables Físico-Químicas Y Microbiológicas De Las Lagunas Del Municipio De Escárcega, Campeche, México. European Scientific Journal, ESJ, 17(25), 116.

https://doi.org/10.19044/esj.2021.v17n25p116

\section{Resumen}

La seguridad hídrica en México enfrenta problemas de contaminación, escases, deterioro ambiental de las cuencas, de las cuales son el resultado del mal uso y aprovechamiento de la población en sus distintas actividades económicas y de uso doméstico. Por tal motivo, el presente trabajo tiene como objetivo principal evaluar la calidad del agua en los principales cuerpos de agua lénticos (lagunas) que abastece a las comunidades del municipio de Escárcega, utilizando energías limpias. Para el logro de este trabajo se muestrearon cinco puntos en distintas lagunas de la mencionada región, para determinar los parámetros físico-químicos (Nitrógeno, Cloruros, pH y Dureza) y microbiológicos (organismos Coliformes Totales, y Fecales (E. coli). Los resultados indican que la calidad del agua en las distintas lagunas del municipio cumple con los límites máximos permisibles (LMP) conforme a la modificación de la NOM-127-SSA1-2000. En relación a los análisis microbiológicos en la etapa confirmatoria se observó la presencia de 
Coliformes fecales (E. coli), en todos los puntos de muestreo de las lagunas. Por otro lado, las pruebas confirmatorias indicaron la presencia de esta bacteria en las distintas diluciones; 1:10, 1:100 y 1:1000 respectivamente, contrastando los resultados conforme a los parámetros de la NMX-AA-042SCFI-2015, demostrando la presencia significativa de Escherichia coli. en las pruebas. Por lo tanto, se concluye que emplear tratamientos térmicos contribuye a la eliminación o desactivación parcial principalmente de bacterias E. coli así como otras bacterias termotolerantes, además este procedimiento combinado con un sistema de recirculación (SRA) y los tratamientos convencionales (Plantas de Tratamientos de Aguas (PTAR), resulta una alternativa sustentable de potabilización del agua de forma eficiente debido a que interviene en el proceso especies bioindicadores ecológicas que permiten la remoción de los microrganismos para el uso doméstico de la población local.

Palabras Clave: Medio Rural, Calidad Del Agua, Lagunas, Parámetros Fisicoquímicos, Microbiológicos, Calentador Solar, Energías Limpias

\title{
Analysis Of The Physical-Chemical And Microbiological Variables Of The Lagoons Of The Municipality Of Escarcega, Campeche, Mexico
}

\author{
Blanca del Rosario Martín Canché (Maestra en Gestión y Administración \\ de Proyectos) \\ Maximiliano Vanoye Eligio (Doctor en Ciencias) \\ Martín Gabriel Chan Palomo (Ingeniero bioquímico) \\ José Luis Guillen Taje (Maestro en Gestión Educativa) \\ José de los Ángeles Aguilar Sánchez (Maestro en Administración) \\ Instituto Tecnológico Superior de Escárcega
}

\begin{abstract}
Water security in Mexico faces problems of contamination, shortages, and environmental deterioration of the basins, of which are the result of the misuse and exploitation of the population in their different economic and domestic activities. For this reason, the main objective of this work is to evaluate the quality of the water in the main bodies of water (lagoons) that supply the communities of the municipality of Escárcega, using clean energy To achieve this work, five points were sampled in different lagoons of the aforementioned region, to determine the physical-chemical parameters (Nitrogen, Chlorides, $\mathrm{pH}$ and Hardness) and microbiological (Total Coliform organisms, and Fecal (E. coli). The results indicate that the water quality in
\end{abstract}


the different lagoons of the municipality complies with the maximum permissible limits (LMP) according to the modification of NOM-127-SSA12000. In relation to the microbiological analysis in the confirmatory stage, the presence of fecal coliforms (E. coli) was observed in all the sampling points of the lagoons. On the other hand, the confirmatory tests indicated the presence of this bacterium in the different dilutions; 1:10, 1: 100 and 1: 1000 respectively, contrasting the results according to the parameters of the NMXAA-042-SCFI-2015, demonstrating the significant presence of Escherichia coli. in tests. Therefore, it is concluded that using heat treatments contributes to the partial elimination or deactivation, mainly of E. coli bacteria as well as other thermotolerant bacteria, in addition to this procedure combined with a recirculation system (SRA) and conventional treatments (Treatment Plants of Waters (WWTP), is a sustainable alternative for water purification in an efficient way because ecological bioindicator species intervene in the process that allow the removal of microorganisms for the domestic use of the local population.

Key Words: Rural Areas, Water Quality, Lagoons, Physicochemical And Microbiological Parameters, Solar Heater, Clean Energy

\section{Introducción}

Gray (1996) menciona que el agua es un elemento vital para la existencia humana, de su uso adecuado depende nuestra salud, alimentación y producción agrícola. México, actualmente enfrenta distintos problemas de abastecimiento de agua por diversas razones, haciendo énfasis en la escasez del recurso y su contaminación, como ocurre en la producción de alimentos en otras partes del mundo, (Peña et al., 2019). Las comunidades rurales no son ajenas a esta problemática, ya que en estas los principales problemas de disponibilidad del agua son el desabasto y su falta de potabilización (SánchezPérez et al., 2000). El abastecimiento de agua a las comunidades rurales proviene principalmente de lagunas, manantiales, ríos, arroyos, ojos de agua, entre otros, estando estas fuentes naturales de agua expuestas a la contaminación, exposición y arrastre de partículas orgánicas e inorgánicas, lo cual ha causado serios problemas en los cuerpos de agua de muchas regiones del mundo (Isaac-Márquez et al., 1994; Ruiz-Marín et al., 2010). El uso de agua contaminada en las distintas actividades domésticas produce un gran número de casos de infección (Fernández, 1981). Distintas investigaciones definen que un contaminante de agua es cualquier sustancia que altera las cualidades físicas, químicas, biológicas o radiológicas del agua, convirtiéndose en una sustancia contaminante cuando excede una concentración o estándar aceptable (Méndez et al., 2009; Ruiz-Marín et al., 2010; Rubio et al., 2015). Datos a nivel mundial registran en promedio 1,8 
millones de personas que mueren anualmente por enfermedades diarreicas, siendo el $88 \%$ de las enfermedades diarreicas producidas por un abastecimiento de agua contaminada con presencia de bacterias como el Vibrio cholerae, Salmonella typhi, Yersinia enterocolitica, virus como el de la hepatitis A y de Norwalk, protozoos importantes como Giardia lamblia, Entamoeba histolytica y Criptosporidium parvum (Félix-Fuentes et al., 2007). Por su parte la Organización Panamericana de la Salud en 1993 mencionó que existen descritas más de 20 enfermedades relacionadas con el agua contaminada, presentando algunas de ellas un alto impacto en términos de morbilidad y mortalidad (OPS, 1993). Considerando el problema que presenta el agua para su abastecimiento a zonas urbanas y rurales, su suministro a estas zonas debe cumplir con parámetros de calidad (físicos, químicos y microbiológicos) establecidos en las normas mexicanas para garantizar su consumo y evitar riesgos a la salud. Las normas mexicanas establecen una serie de parámetros fisicoquímicos y biológicos que se deben de cumplir en la explotación de agua para uso y consumo humano proveniente de distintos cuerpos de agua. En 2007, el Sistema Nacional de Información del Agua reportó resultados de bioquímica de oxígeno, demanda química de oxígeno y sólidos suspendidos totales de 1014 sitios de monitoreo de la calidad del agua operados por CONAGUA manifestando que la calidad del agua es de buena calidad a fuertemente contaminada (Ruiz-Marín et al., 2010), por lo que concluyeron que el agua extraída en México es en muchas ocasiones enviada directamente para su consumo sin antes verificar su calidad.

En el sureste mexicano se han realizado distintos estudios enfocados a evaluar la calidad del agua que se consume en la región. Sánchez et al. (2016) realizó un estudio en Quintana Roo, México y sus estados vecinos (Campeche y Yucatán), mencionando que los acuíferos son la principal fuente de abastecimiento de agua para todas las actividades humanas que se realizan en zonas urbanas y rurales, sin embargo, estas fuentes de agua son altamente vulnerables a la contaminación, permitiendo la infiltración y arrastre de contaminantes, además, el crecimiento demográfico y económico impulsado por la industria turística propicia una mayor demanda de agua, al mismo tiempo una creciente generación de aguas residuales y desechos sólidos, obteniendo en sus resultados que ninguna de las muestras analizadas estuvo fuera de los límites permisibles de la NOM-127-SSA1-1994. Por su parte, Benítez et al. (2011) analizó la calidad del agua en el estado de Campeche, reportando que los valores de sólidos totales disueltos, $\mathrm{pH}$ y sulfatos un tercio de los pozos rebasaron los límites permisibles de la normatividad mexicana, mientras que el resto de los sitios no excedieron los límites permisibles para nutrientes y metales pesados. De igual forma mencionaron que todos los pozos presentaron contaminación por bacterias coliformes, esto debido principalmente a la proliferación de basureros a cielo abierto y la deficiente 
red de alcantarillado, así como al cambio de uso del suelo en el área. Sin embargo, Cisneros (2007) ha comentado que el estudio de la calidad del agua, ha sido un tema público desde el año 1990, y que no ha sido clara la forma de evaluarlas provocando una dificultad de conocer cómo ha cambiado. En el estado de Campeche la calidad del agua potable se rige bajo la ley de agua potable y alcantarillado del estado de Campeche emitido por el Poder Legislativo del Estado de Campeche, en su artículo 10 menciona que con el objeto de reducir la contaminación y atender la degradación de la calidad original de las aguas dentro del "Sistema de Agua Potable y Alcantarillado del Estado”, las autoridades estatales y municipales, así como los organismos a que se refiere la presente ley, en el ámbito de su competencia, promoverán el establecimiento de sistemas de potabilización y, en su caso, de tratamiento de aguas residuales y manejo de lodos, así como el fomento de sistemas alternos que sustituyan al alcantarillado sanitario, cuando éste no pueda construirse; y la realización de las acciones necesarias para conseguir y mantener un adecuado nivel de calidad de las aguas (PLEC, 2020). El objetivo principal de este trabajo de investigación fue evaluar la calidad del agua en los principales cuerpos de agua que abastecen a las comunidades del Municipio de Escárcega, para proponer estrategias de potabilización utilizando las energías limpias.

\section{Materiales y métodos \\ Descripción del área de estudio}

De acuerdo con la información documentada por el INEGI (2009), el municipio de Escárcega, Campeche, México, se ubica entre los paralelos $18^{\circ} 10^{\prime}$ y $19^{\circ} 01^{\prime}$ de latitud norte; los meridianos $90^{\circ} 03^{\prime}$ y $91^{\circ} 02^{\prime}$ de longitud oeste; altitud entre 100 y $200 \mathrm{~m}$. De igual forma, se registra que la temperatura promedio ronda entre el $26^{\circ}-28^{\circ} \mathrm{C}$, con una precipitación total anual de 1100 - $1500 \mathrm{~mm}$, con un clima considerado de tipo Cálido subhúmedo con lluvias en verano, de humedad media (99.97\%) y cálido subhúmedo con lluvias en verano, de mayor humedad (0.03\%). Registrando un suelo dominante de Leptosol (47.59\%), Vertisol (37.71\%), Phaeozem (11.41\%), Gleysol (1.86\%), Luvisol (0.19\%) y No aplicable (0.11\%).

El área de estudio abarcó distintas lagunas que forman parte del municipio de Escárcega (Fig. 1), siendo la más representativa la laguna Silvituc ubicada en las coordenadas $18^{\circ} 37^{\prime} 21^{\prime \prime} \mathrm{LN}$ y $90^{\circ} 16^{\prime} 26^{\prime \prime} \mathrm{LO}$, con una altitud de $54 \mathrm{msnm}$, perteneciente en el municipio de Escárcega, Campeche, México. Por lo que, se considera el cuerpo de agua interior más grande del estado, debido a que colinda con los puntos que se tomaron para muestrear; Adolfo López Mateos, Chan Laguna, Laguna Noh. De igual forma se hicieron otros muestreos en la Laguna Matamoros ubicado en elegido con el mismo nombre $\left(18^{\circ} 35^{\prime} 02^{\prime \prime} \mathrm{LN} 90^{\circ} 38^{\prime} 43^{\prime \prime}\right.$ LO $\left.107 \mathrm{msnm}\right)$ y la Laguna de Miguel Hidalgo (18 $38^{\prime} 01.55^{\prime \prime} \mathrm{LN} 90^{\circ} 45^{\prime} 00.04^{\prime \prime}$ LO con altitud de $99 \mathrm{msnm}$ ) 
localizada en la cabecera Municipal, siendo esta última un cuerpo de agua superficial. De la misma manera, se registró in situ en cada sitio la temperatura del agua y del aire ( $\mathrm{T}$ y Ta, respectivamente, ${ }^{\circ} \mathrm{C}$ ) en temporada de lluvias.
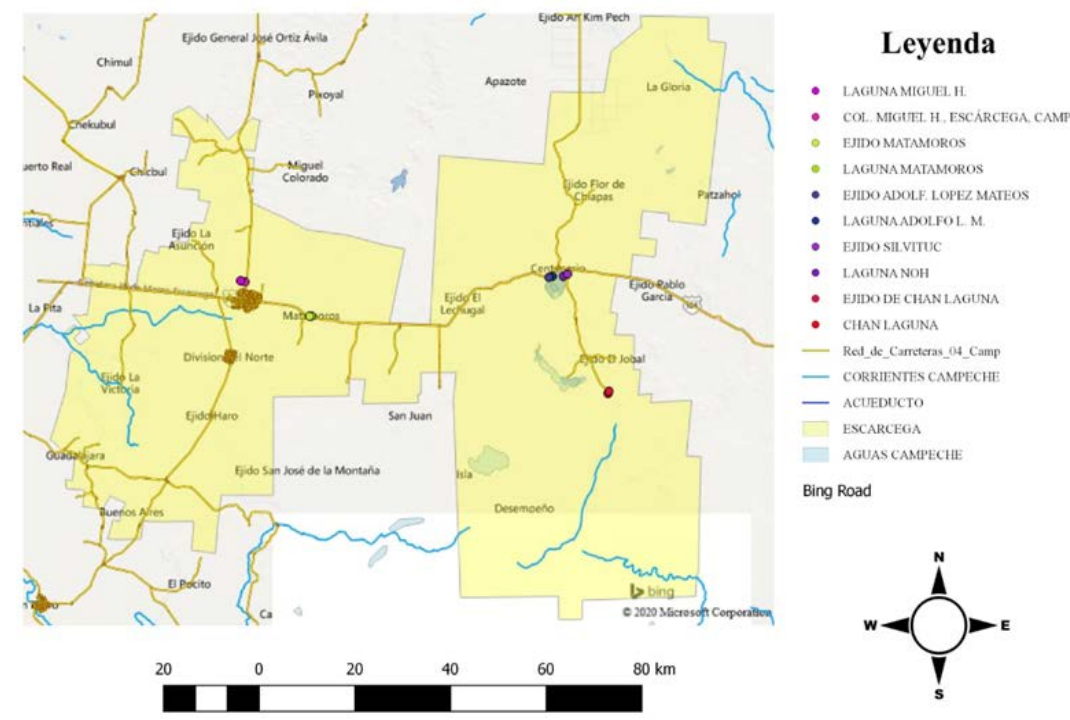

Fig. 1. Distribución geográfica de las Lagunas, Escárcega, Campeche, México.

Fuente:(Earth, 2020)

\section{Muestreo en campo}

Como primera actividad se seleccionaron los cinco puntos de muestreo en las lagunas más representativas del municipio de Escárcega, Campeche, México, para conocer sus propiedades físico-químicas y microbiológicas de los cuerpos de agua. En donde se siguió un protocolo para la toma y resguardo de la muestra registrándose los parámetros determinantes regidos por las Normas Mexicanas. En la medición de nitrógeno total Kjeldahl en aguas naturales, residuales y residuales tratadas para la medición de Nitrógeno Total, se realizó con base a la NMX-AA-026-SCFI-2010, para conocer el grado de descomposición de la materia orgánica, así como para conocer el índice de contaminación de los derivados compuestos nitrogenados (productos de amonio, nitratos, etc.), que está basado en la digestión acida de la muestra, seguido de una destilación en medio alcalino, finalizando la titulación para obtener el nitrógeno Total. Asimismo, se determinó los cloruros totales presentes en agua de las lagunas bajo la aplicación de la metodología de la NMX-AA-073-SCFI-2001. Para la medición del pH se utilizó el método directo electrométrica en el sitio de muestreo conforme a la NMX-AA-008SCFI-2016, siendo uno de los más importantes para la evaluación de las propiedades corrosivas de un medio acuático. Por otro lado, se aplica el 
método de análisis para la determinación de dureza total en aguas naturales, residuales y residuales tratadas conforme a los procedimientos establecidos en la NMX-AA-072-SCFI-2001.

Finalmente procedió a la cuantificación de microorganismos Coliformes totales, organismos coliformes Fecales (termotolerantes) y E. coli según la (NMX-AA-042-SCFI-2015). Cabe señalar que estas normativas aplicadas en cada procedimiento permitieron comparar los Límites Máximos Permisibles establecidos en la modificación de la NOM-127-SSA1-2000, para conocer su cumplimiento.

\section{Criterio para la selección del punto de muestreo}

Derivado a lo anterior se tomaron de referencia los cuerpos de agua más representativos del municipio de Escárcega, Campeche, México, para determinar sus características físicas-químicas y microbiológicas. Cabe señalar que los sitios de muestreo se encuentran dentro de una zona de influencia urbana, por lo que se observa una estrecha relación con su uso doméstico, el cual se realiza sin previo tratamiento pudiendo originar tanto enfermedades como efectos medioambientales. Por tal motivo, se pretende aplicar las energías limpias para tratarlas y contrarrestar la presencia de los microorganismos termotolerantes Coliformes Totales y Coliformes Fecales.

\section{Resultados y discusión}

Derivado de la revisión bibliográfica, se enlista los parámetros conforme a los LMP de la calidad y tratamiento a que debe someterse el agua para su potabilización, de acuerdo a la modificación de la NOM-127-SSA12000 (Tabla 1).

Tabla 1. Características fisicoquímicas y microbiológicas, según modificación de la NOM-127-SSA-2000

\begin{tabular}{|c|c|}
\hline Características & Límite Máximos Permisibles \\
\hline Nitrógeno total & No establece LMP \\
\hline Nitratos (como N) & $10,00 \mathrm{Mg} / \mathrm{l}$ \\
\hline Cloruros Totales & $250,00 \mathrm{Mg} / \mathrm{l}$ \\
\hline $\mathrm{pH}$ & $6,5-8,5 \mathrm{Mg} / \mathrm{l}$ \\
\hline $\begin{array}{c}\text { Dureza Total } \\
\text { (como CaCO3) }\end{array}$ & $500,00 \mathrm{Mg} / \mathrm{l}$ \\
\hline Organismos Coliformes totales & Ausencia o no detectables \\
\hline $\begin{array}{c}\text { E. coli o coliformes fecales u } \\
\text { organismos termotolerantes }\end{array}$ & Ausencia o no detectables \\
\hline
\end{tabular}

Se aplicó la metodología conforme a los parámetros de la NMX, registrando los resultados de la caracterización del agua de las lagunas (Tabla 2). Asimismo, se contrastaron los LMP de acuerdo a la modificación de la NOM-127-SSA1-2000 referente a los parámetros seleccionados. 
Tabla 2. Determinación de parámetros fisicoquímicos y microbiológicos

\begin{tabular}{|c|c|c|c|c|c|c|c|c|c|}
\hline & \multicolumn{6}{|c|}{ Parámetros Fisicoquímicos } & \multicolumn{3}{|c|}{ Parámetros Microbiológicos confirmatorios } \\
\hline Sitio & $\begin{array}{c}\text { Nitrógeno } \\
\text { Total } \\
\mathrm{ml} / / \\
\end{array}$ & $\begin{array}{c}\text { Cloruros Totales } \\
\text { Cl-mg/L }\end{array}$ & $\mathrm{pH}$ & $T^{\circ}$ ambiental & $T^{\circ}$ del agua & $\begin{array}{l}\text { Dureza Total } \\
\mathrm{mg} / \mathrm{ICaCO} 3\end{array}$ & $\begin{array}{l}\text { NMP (Número más } \\
\text { probable) }\end{array}$ & $\begin{array}{c}\text { organismos } \\
\text { Coliformes } \\
\text { totales }\end{array}$ & \begin{tabular}{|c|} 
organismos \\
coliformes Fecales
\end{tabular} \\
\hline Laguna Noh & 1.65 & 0.0595 & 7.65 & $30^{\circ} \mathrm{C}$ & $23.4^{\circ} \mathrm{C}$ & 500 & $\begin{array}{c}\geq 2400 \\
\mathrm{NMP} / 100 \mathrm{ML}\end{array}$ & + & + \\
\hline Laguna Matamoros & 2.8 & 0.0645 & 7.8 & $30^{\circ} \mathrm{C}$ & $23.5^{\circ} \mathrm{C}$ & 600 & $\begin{array}{c}\geq 2400 \\
\mathrm{NMP} / 100 \mathrm{ML}\end{array}$ & + & + \\
\hline Laguna Miguel Hidalgo & 2.5 & 0.0446 & 7.68 & $31^{\circ} \mathrm{C}$ & $23.6^{\circ} \mathrm{C}$ & 500 & $\begin{array}{c}\geq 2400 \\
\mathrm{NMP} / 100 \mathrm{ML}\end{array}$ & + & + \\
\hline Laguna Adolfo López Mateo & 2.2 & 0.0595 & 7.38 & $31^{\circ} \mathrm{C}$ & $23.5^{\circ} \mathrm{C}$ & 450 & $\begin{array}{c}210 \\
\mathrm{NMP} / 100 \mathrm{ML}\end{array}$ & + & + \\
\hline Laguna Chan Laguna & 1.7 & 0.0397 & 7.62 & $30^{\circ} \mathrm{C}$ & $23.5^{\circ} \mathrm{C}$ & 500 & $\begin{array}{c}210 \\
\mathrm{NMP} / 100 \mathrm{ML}\end{array}$ & + & + \\
\hline
\end{tabular}

En la tabla 2, se representan los resultados obtenidos de los parámetros fisicoquímicos y microbiológicos de las lagunas en el municipio. Respecto a los resultados obtenidos del Nitrógeno Total, referente a la (NMX-AA-026SCFI-2010), se observa que la norma NOM-127-SSA1-2000 no establece controles específicos para el Nitrógeno Total, pero si establece LMP de nitratos, los cuales son productos derivados de la oxidación del Nitrógeno. Dado lo anterior, se toma como referencia los valores controlados por la Norma establecida, donde indica que el LMP es de 10,00 mg/l, de Nitratos $\left(\mathrm{NO}_{3}\right)$, contrastándolas con las muestras se identificó que los valores son inferiores para la transformación del Nitrógeno, por lo que se cumple con la norma. En el caso de cloruros, se contrasta con la información establecida en el apartado 4.3.1, registrado en la modificación de la NOM-127-SSA1-2000. En el caso de la medición de cloruros, se observó que están por debajo de los límites que marca la norma, infiriendo que la muestra es libre de cloruros. Los resultados de $\mathrm{pH}$ medidos en campo se encuentran dentro de los LMP, con una tendencia en alcalinidad en las aguas, método aplicado de acuerdo a la NMXAA-008-SCFI-2016, mismos que se contrasta el resultado con los LMP establecidos en el apartado 4.3.1 de la norma NOM-127-SSA1-2000. En cuanto al parámetro de Dureza, donde se considera a los compuestos de carbonatos (Carbonato de Calcio y de Magnesio), que son de mayor control en la actividad agrícola por su tendencia a alcalinizar el suelo (Appelo \& Postma, 1991). Los resultados muestran que cuatro de los cinco sitios de muestreo se encuentran dentro de los LMP (500 mg/l), con excepción de la Laguna Matamoros, que se encuentra por arriba del LMP (600 mg/ $\mathrm{CaCO}_{3}$ ), sin embargo, las restantes se encuentran al límite de las especificaciones máximas del criterio normativo en estudio. Tomando en consideración lo antes mencionado, es importante señalar que las lagunas en estudio son aptas para aplicar tratamiento térmico debido a que contribuye a la eliminación o 
desactivación parcial principalmengte de la bacteria E. Coli, a sí como las bacterias termotolerantes, aunado a este proceso es de suma importancia mencionar que el proceso de biofiltación contribuye a la purificación de las agua, Wong (2019), ha mencionado que el empleo de un biofiltro de flujo horizontal es un método efectivo para la remoción de metales pesados y reducción de las concentraciones de Demanda Biológica de Oxigeno ( $\mathrm{DBO}_{5}$ ). Además Mallama et al. (2011), demuestran que la filtración en membranas empleando organismos con ciertos beneficios biológicos como lo es la almeja de agua dulce (Anodontites tortolis), es considerada una alternativa para disminuir la carga de E. coli. Por su parte, Villacorte et al., 2015, hace mencion que los procedimientos algales son de gran importancia debido a sus variaciones en las concentraciones de sustancias orgánicas en los cuerpos de agua, de las cuales cansan interferencia en la operación de los procesos de tratamiento. Asímismo, Henderson, et al 2008, describe que las interferencias sobrecargan los tanques de sedimentación, además de sufrir cambios de $\mathrm{pH}$ que dificultan la operación, alteraciones en la floculación especialmente por la materia orgánica excretada, colmatación y variación de tiempos de operación en filtros, generación de precursores de subproductos de desinfección (SPD) e incremento en la dosis de cloro.

Correa (2008), enfatiza que los sistemas convencionales contribuyen a mejorar la eficiencia de los tatamientos del agua, de los cuales se resalta la PTAR de Puerto Mallarino; este utiliza desarenación, adsorción con carbón activado, precloración, coagulación, floculación, sedimentación, filtración, desinfección y estabilización química. Cabe señalar que el biofiltro forma parte esencial del (SRA), resultando de la actividad bacteriana encargada de convertir en nitritos y nitratos de los cuales resultan menos tóxicos para los organismos.

Por otro lado, una vez aplicada el procla pasteurización se recomienda realizar pruebas analíticas para conocer si el proceso también aporta sedimentación de carbonato de calcio, por el efecto de interacción física de ionización. La medición de los parámetros físicos, químicos y microbiológicos en el agua para consumo humano, es una actividad constante que se realiza a nivel internacional. A nivel nacional se ha documentado por la CONAGUA (2018) múltiples sitios de muestreo con respecto a los ecosistemas lenticos, de los cuales, para el estado de Campeche, el Ejido Adolfo López Mateo que forma parte del municipio de Escárcega, mostró presencia de E. coli y Coliformes Totales en el año 2012, sin embargo, en el mes de marzo y julio del 2018, según los informes publicados por la CONAGUA, reportaron que ya no tiene presencia de estos microrganismos, en contraste a los análisis realizado en el 2020 en este estudio en las distintas lagunas del municipio Escárcega, se obtuvo como resultado, la presencia de estos microorganismos, por lo que se considera que es debido a escorrentía asociada a la cercanía de 
la población adyacentes a la laguna. La presencia de microorganismos coliformes en los distintos cuerpos de agua en el territorio mexicano ha sido reportado en diversas investigaciones, las cuales menifiestan constantemente sobre la contaminación microbiológica existente en los ecosistemas lénticos se caracteriza por la identificación de organismos indicadores como las bacterias Coliformes Totales (CT) y Fecales (CF). Por su parte Félix-Fuentes et al. (2007) en su estudio en comunidades rurales del sur de Sonora, demostró que en las comunidades de Aduana y Melchor Ocampo existe presencia significativa de CF, los cuales el 99\% corresponde a 83 muestras y de un $86 \%$ de 72 muestras respectivamente, registrando los parámetros fuera de norma, siendo el principal causante de enfermedades de infección intestinal (gastroenteritis) a la población local, derivado del uso y consumo de estas aguas sin tratamiento de depuracióna, por lo que en su estudio en el muninicipio con Etchojoa se registró un 6\% de CF de las 21 muestras tomadas aleatoriamente de tres comunidades durante un año, dada la desinfección por cloro que realiza en condiciones normales. Es importante considerar estos procesos térmicos, de recirculación y PTAR para la eliminación de los microorganismos de CF y CT , ya que de no tratar el agua, estos se pueden ver reflejados en la producción de alimentos, tal es la producción de alimentos (Hannibal et al., 2015). Asimismo, se aplicó la metodología propuesta según la NMX-AA-042-SCFI-2015, para la evaluación en la determinaciónde organismos coliformes totales, organismos coliformes Fecales (termotolerantes) y Escherichia coli (tabla 2). Los resultados preliminares demostraron presencia de microorganismos patógenos termotolerantes en la etapa de prueba presuntiva (Tabla 3), quedando registrado el grado de contaminación microbiana de las muestras de agua sometidas a una temperatura de $44,5 \pm 0.5^{\circ} \mathrm{C}$. Estos resultados coinciden con lo reportado por la CONAGUA (2018), quien manifestó la presencia de Coliformes Fecales en 3751 sitios muestreados, de los cuales se hace hincapié en el apartado XII que corresponde a la Península de Yucatán, se registró presencia muy alta de microorganismos termotolerantes contaminantes (0.5\%). Distintas investigaciones (Méndez et al., 2009; Ruiz-Marín et al., 2010; Rubio et al., 2015), han registrado bacterias coliformes en algunas de las principales fuentes de abastecimiento de agua del estado de Campeche, debido a la presencia de contaminación bacteriológica, originada principalmente por la acumulación de residuos inorgánicos a cielo abierto, así como el deficiente manejo del sistema de agua y al impacto que deja la zona de influencia por el cambio de uso de suelo. Dichas investigaciones registran que el $100 \%$ de cuerpos acuíferos excedieron los LMP establecidos en la norma, con valores que van desde 2 hasta 240,000 NMP/100 ml-1., resaltando que Candelaria fue el municipio que registró la mayor concentración de coliformes totales y fecales a diferencia del resto de los sitios de muestreo. Asimismo, se realizaron 
pruebas confirmatorias para validar la presencia real de bacterias conforme a la referencia de los LMP en el apartado 4.1.4 de la norma NOM-127-SSA12000, registrando la presencia significativa de estos microrganismos termotolerantes la temperatura de incubación es de $44.5 \pm 0.5$, causantes de infecciones gastrointestinales nocivas para el ser humano, donde CONAGUA (2018) hace mención que se distinguen por ser bacterias aerobias y anaerobias facultativas, no esporuladas, de forma de bacilo corto que fermentan la lactosa con producción de gas en 48 horas a $35 \pm 0.5^{\circ} \mathrm{C}$.

La necesidad de mejorar la calidad del agua para consumo humano a través del control de distintos parámetros ha llevado a los investigadores a generar técnicas, métodos e instrumentos que apoyen para esta actividad, sin embargo, también es fundamental hoy en día considerar el uso de las energías limpias al aplicar métodos para el control de microorganismos (coliformes totales y fecales) que se presentan en los cuerpos de agua. Desde este enfoque, Hermosillo-Villalobos, (2001), hace mención que una de la forma más eficiente de desactivar o eliminar los microorganismos presentes en al agua es a través de la pasteurización mediante calentadores solares, siendo una alternativa sustentable para las comunidades que no tienen acceso al agua entubada; un ejemplo de ello es el uso de estufas solares de reflectores con un apropiado manejo logra temperaturas de ebullición del agua con el simple hecho de emplear la energía solar, aportando enormemente a la población local una alternativa viable que contribuya a la reducción de estos microorganismos termotolerantes presentes en el agua. Como se demostró en este estudio, mediante la aplicación de un proceso térmico solar, se pudo registrar la disminución de microorganismos termotolerantes (E. Coli), en rangos de temperatura de $65-73^{\circ} \mathrm{C}$ que alcanzó el proceso térmico implementado. E. Coli es considerada como el principal indicador microbiano presente en las heces de humanos y animales de sangre caliente (contaminación fecal), (Cordova Castañeda, 2017), por lo que los resultados sugieren a su vez que otras especies termotolerantes de distintos géneros (Escherichia, Streptococcus, Klebsiella, Enterobacter y Citrobacter), muy posiblemente también disminuyan su población inclusive las desactive, como se considera en este estudio y otras investigaciones, (Márquez-Bravo, 1998; Pullés, 2014; Berrio_Moreno 2018; Zárate Sarapura, 2021).

Así mismo se menciona que diversos microorganismos tolerantes mueren a varias escalas de temperaturas; por ejemplo, la amiba en menos de una hora a $50^{\circ} \mathrm{C}$ o de forma instantánea a $57^{\circ} \mathrm{C}$; la salmonela en una hora a $55^{\circ} \mathrm{C}$ y en $20 \mathrm{~min}$. a $60^{\circ} \mathrm{C}$., también Márquez-Bravo (1998) menciona que este proceso destruye a organismos coliformes $y$ otras bacterias no termorresistentes transmitidos por el agua contaminada entre un rango de temperatura de $62.8^{\circ} \mathrm{C}$ por 30 min y de $71.7 \%$ por 15 min son necesarios para reducirlas. Se realizó una prueba final de proceso térmico solar a las aguas de 
los sitios de muestreo, para disminuir significativamente los microorganismos termotolerantes presentes en ella, mediante el uso de recipientes de diferentes materiales (aluminio y Zinc), por lo que se observó que las condiciones de temperatura de $65-75^{\circ} \mathrm{C}$ y un tiempo de $20-30$ min, son efectivo y logran su inactivación o muerte instantánea indistintamente del material utilizado, como fue confirmado con las pruebas microbiológicas, estos resultados coinciden con los expresados por Márquez-Bravo (1998). Es importante mencionar que no es preciso que el agua logre el grado de ebullición para disminuir la carga bacteriana.

Por lo anterior, se recomienda emplear tratamientos térmicos que contribuyan a la eliminación o desactivación parcial principalmente de bacterias E. coli así como otras bacterias termotolerantes, además este procedimiento combinado con un sistema de recirculación (SRA) y los tratamientos convencionales (Plantas de Tratamientos de Aguas (PTAR), para disminuir en gran medida los riesgos microbiológicos en la población, mediante el uso de las energías limpias que permitan disminuir significativamente la contaminación por estos microorganismos termotolerantes.

Tabla 3. Pruebas confirmatorias microbiológicas para E. Coli

\begin{tabular}{|c|c|c|c|c|c|}
\hline \multirow{2}{*}{ DILUCIÓN } & \multicolumn{5}{|c|}{ MUESTRAS } \\
\cline { 2 - 6 } & M1 & M2 & M3 & M4 & M5 \\
\hline $1: 10$ & $3+$ & $1+$ & $3+$ & $3+$ & $3+$ \\
\hline $1: 100$ & $3+$ & $1+$ & 0 & $3+$ & $3+$ \\
\hline $1: 1000$ & $3+$ & $1+$ & 0 & $3+$ & $3+$ \\
\hline $\begin{array}{c}\text { RESULTADOS } \\
\text { norma 042 }\end{array}$ & $\geq 2400$ & 11 & 23 & $\geq 2400$ & $\geq 2400$ \\
\hline
\end{tabular}

Finalmente, se diseñó un prototipo tipo calentador solar (proceso térmico) elaborados con distintos materiales (aluminio y zinc), para disminuir significativamente la contaminación por microorganismos termotolerantes, mediante el uso de las energías renovables y de material reciclado. Hoy en día para alcanzar la sostenibilidad de un sistema es fundamental emplear materiales y recursos ecológicos que contribuyan a la conservación del ecosistema (Malla et al., 2019), por lo contrario de continuar utilizando los sistemas tradiciones conlleva al deterioro del medio ambiente.

\section{Conclusión}

La importancia de realizar estudios sobre la calidad del agua empleada para el consumo humano, es un requisito responsable y regulatorio aplicado para evitar problemas de salud. Como antecedente a lo anterior, se puede hacer mención que existe un órgano regulatorio conocido como la Comisión Nacional del Agua (CONAGUA), cuya responsabilidad es trabajar adjunto con la Comisión Federal de Protección contra Riesgos Sanitarios (COFEPRIS) 
para garantizar que dicho líquido vital cubra las características de inocuidad alimentaria.

Sin embargo, existe un sector de la población aislada de las zonas urbanas que usan agua natural de manera directa a partir de mantos de almacenamiento como embalses, lagos y ríos. de acuerdo al contexto anterior, surge la importancia de realizar un número mayor de investigaciones aplicadas a las características de la composición del agua natural, para realizar proyectos con procedimientos sustentables y económicamente disponibles de potabilización, para dicho sector comunitario. El resultado del estudio, concluye en emplear tratamientos térmicos que contribuyan a la eliminación o desactivación parcial principalmente como organismos unicelulares sin formas de resistencia, tal es el caso del E. coli y de otras bacterias termotolerantes. Sin embargo, este procedimiento combinado con un sistema de recirculación (SRA) y los tratamientos convencionales (Plantas de Tratamientos de Aguas (PTAR), resulta una alternativa sustentable de potabilización del agua de recursos lénticos de forma eficiente debido a que interviene en el proceso especies bioindicadores ecológicas que permiten la remoción de los microorganismos para el uso doméstico de la población local.

\section{Agradecimientos}

Nuestro sincero agradecimiento al Laboratorio de Industrias Alimentarias del Instituto Tecnológico Superior de Escárcega, por facilitar el uso de sus materiales y equipos para llevar a cabo las pruebas físico-químicas y microbiológicas de la calidad del agua de las Lagunas del Municipio de Escárcega. Así como al Instituto Tecnológico Superior de Escárcega a través de la División de estudios de la Carrera Ingeniería en Energías Renovables, por brindarnos los recursos necesarios para concretar el proyecto. Finalmente, pero no menos importante, agradecer por contribuir en el desarrollo de las pruebas del proyecto a los estudiantes de la carrera Ingeniería en Energías Renovables al Br. Ismael Molar Fernández y al Br. Luis Vázquez Oleta.

\section{References:}

1. Barrera-Escorcia, G., Fernández-Rendón, C. L., Wong-Chang, I., \& Ramírez Romero, P. (2013). La sensibilidad del grupo coliforme como indicador de la presencia de enterobacterias patógenas en cuatro cuerpos acuáticos de México. Hidrobiológica, 23(1), 87-96.

2. Benítez, J. A., Lara-Flores, M., Amábilis, L., Ben-Arie, J., VidalMaldonado, J. A., Cen-Poot, B. T., Acevedo, V. M., Rendón-Von, J. O., \& Sonda-Santos, K. (2011) .An assessment of water quality (NH4 + , NO2 - , NO3 - , TP, SO4, coliform bacteria and heavy metals) of the main water supplies in the state of Campeche. Tropical and Subtropical Agroecosystems, 13: 187 - 197. 
3. Berrio_Moreno, S. (2018). Estudio de la calidad microbiológica de hábitats lénticos de la provincia de Jaén.

4. Cisneros, B. E. J. (2007). Información y calidad del agua en México. Trayectorias, 9(24), 45-56.

5. Cordova Castañeda, M. A. (2017). Calidad del agua en la microcuenca del río Challhuahuacho comparado con los estándares de calidad ambiental para riego y bebedero (eca 3) en la zona de Challhuahuacho, Cotabamba-Apurímac-2016.

6. Correa, L. F. M. (2008). Optimización del proceso de floculación en la planta de tratamiento de agua potable el dorado de Bogotá (Doctoral dissertation, Uniandes).

7. DOF. (2000). Norma Oficial Mexicana NOM-127-SSA1-1994. Límites permisibles de calidad y tratamientos a que debe someterse el agua para su potabilización. D.F., México. Recuperado el 14 de octubre de 2020

http://www.siapa.gob.mx/sites/default/files/norma_oficial.pdf

8. Earth, G. (20 de 11 de 2020). Obtenido de https://earth.google.com

9. Félix-Fuentes, A., Campas-Baypoli, O. N., Aguilar-Apodaca, M. G., \& Meza-Montenegro, M. M. (2007). Calidad microbiológica del agua de consumo humano de tres comunidades rurales del sur de sonora (México). Revista Salud Pública y Nutrición, 8(3), 1-13.

10. Fernández, E. 1981. Microbiología Sanitaria: Agua y sus Alimentos. Vol. 1 Universidad de Guadalajara. Pp. 39-56,159-170.

11. Giraldo Garzón, A. C. (2016). Evaluación de la interferencia de florecimientos algales en la remoción de AOM durante el proceso de coagulación en sistemas de potabilización (Master's thesis, Maestría en Ingeniería Ambiental).

12. Gray, N.F. 1996. Calidad del agua potable (Problemas y soluciones). Editorial Acriba Zaragoza, España. Pp. 154-160

13. Hannibal, B., Santillán, A., Mercy, A., Ramos, E., Paola, V., \& Rincon, A. (2015). Aprovechamiento del suero de leche como bebida energizante para minimizar el impacto ambiental. European Scientific Journal, 11(26).

14. Henderson, R., Chips, M., Cornwell, N., Hitchins, P., Holden, B., Hurley, S., ... y Jefferson, B. (2008). Experiencias de algas en aguas del Reino Unido: una perspectiva de tratamiento. Revista de agua y medio ambiente , 22 (3), 184-192.

15. Hermosillo-Villalobos, J. J. (2001). Agua potable para microcomunidades con energía solar.

16. INEGI, Instituto Nacional de Estadística, Geografía e Informática. (2009). Prontuario de información geográfica municipal de los Estados 
Unidos Mexicanos, Escárcega, Campeche. https://www.inegi.org.mx/ consultado el 09 de diciembre de 2020.

17. Isaac-Márquez AP, Lezama-Dávila CM, Ku-Pech PP, Tamay-Segovia P. (1994). Calidad sanitaria de los suministros de agua para consumo humano en Campeche. Salud Publica Mex, 36, 355-361.

18. Malla, O., Hidalgo, C., \& Vásconez, R. Diseño De Un Modelo De Vivienda Ecológica Con Bambú Para La Zona Rural De Yantzaza Zamora Chinchipe, Ecuador.

19. Mallama Leyton, J. R., \& Guzmán Alvis, A. I. (2011). Clearance rate of faecal coliforms by netropical freshwater clam. Acta Agronómica, 60(1), 76-83.

20. Márquez-Bravo, L. G. (1998). Desinfección solar. In En memorias de Simposio Regional sobre Calidad del Agua: Desinfección Efectiva. Lima, CEPISOPS (pp. 1-22).

21. Méndez, J. P., Ramírez, C. A. G., Gutiérrez, A. D. R., \& García, F. P. (2009). Contaminación y fitotoxicidad en plantas por metales pesados provenientes de suelos y agua. Tropical and subtropical Agroecosystems, 10(1), 29-44.

22. Mexicana, N. (2010). NMX-AA-026-SCFI-2010. Análisis De AguaMedición De Nitrógeno Total Kjeldahl En Aguas Naturales, Residuales Y Residuales Tratadas - Método De Prueba -(CANCELA A LA NMX-AA-026-SCFI-2001). Recuperada el 20 de noviembre de 2020.

https://www.gob.mx/cms/uploads/attachment/file/166772/NMX-AA026-SCFI-2010.pdf

23. Mexicana, N. (2015). NMX-AA-042-SCFI-2015. Análisis De Agua Enumeración De Organismos Coliformes Totales, Organismos Coliformes Fecales (Termotolerantes) Y Escherichia Coli -Método Del Número Más Probable En Tubos Múltiples (Cancela A La NmxAa-42-1987). Recuperada el 16 de diceimbre de 2020 https://www.gob.mx/cms/uploads/attachment/file/166147/nmx-aa042-scfi-2015.pdf

24. Mexicana, N. (2016). NMX-AA-008-SCFI-2016. Análisis de agua. Medición del $\mathrm{pH}$ en aguas naturales, residuales y residuales tratadas.Método de prueba (Cancela a la NMXAA-008-SCFI-2011). Secretaria de Economía. México, DF. Recuperado el 17 de noviembre de 2020 https://www.gob.mx/cms/uploads/attachment/file/166767/NMX-AA008-SCFI-2016.pdf

25. Mexicana, N. O. (2001). NMX-AA-073-SCFI-2001. Análisis de aguadeterminación de cloro total en agua natural, aguas residuales y tratamiento de aguas residuales-método de prueba. Recuperado el 15 de diciembre de 2020 . 
https://www.gob.mx/cms/uploads/attachment/file/166789/NMX-AA073-SCFI-2001.pdf

26. OPS, Organización Panamericana de la Salud, Organización Mundial de la Salud. (1993). Agua, nuestro planeta y nuestra salud. Informe de la Comisión de Salud y Medio Ambiente de la Organización Mundial de la Salud. Washington, D.C.: OPS, OMS, 1993.

27. Peña, R. F., León, J. E., Cuesta Subía, H. X., \& Rivadeneira Ruales, J. E. (2019). Riego deficitario por goteo a niveles de humedad del suelo en la papa (Solanum spp.) variedad victoria, Riobamba, Ecuador.

28. PLEC, Poder Legislativo del Estado de Campeche. (2020). Ley de agua potable y alcantarillado del estado de Campeche

https://www.escarcega.gob.mx/transparencia/smapae/2014/LEY\%20 DE\%20AGUA\%20POTABLE\%20DEL\%20ESTADO\%20CAMPEC HE.pdf. Consultado el 01 de noviembre de 2020.

29. Pullés, M. R. (2014). Microorganismos indicadores de la calidad del agua potable en Cuba. Revista CENIC. Ciencias Biológicas, 45(1), 2536.

30. Rubio, A. H. O., Balderrama, T. L. R., Burrola, B. E., Aguilar, P. G. N., \& Saucedo, T. R. A. (2015). Niveles de contaminación del agua potable en la cabecera municipal de Ascensión, Chihuahua, México. Nova scientia, 7(14), 178-201.

31. Ruiz-Marín, A., Rodríguez-Barradas, E., \& Canedo-López, Y. (2010). Variabilidad temporal de cloro residual y presencia de Fe, Cu y Mn en una red de distribución de agua potable en Cd. del Carmen, Campeche.

32. Sánchez, J. A., Álvarez, T., Pacheco, J. G., Carrillo, L., \& González, R. A. (2016). Calidad del agua subterránea: acuífero sur de Quintana Roo, México. Tecnología y ciencias del agua, 7(4), 75-96.

33. Sánchez-Pérez, H. J., Vargas-Morales, M. G., \& Méndez-Sánchez, J. D. (2000). Calidad bacteriológica del agua para consumo humano en zonas de alta marginación de Chiapas. salud pública de México, 42, 397-406.

34. Villacorte, L. O., Ekowati, Y., Neu, T. R., Kleijn, J. M., Winters, H., Amy, G., ... \& Kennedy, M. D. (2015). Characterisation of algal organic matter produced by bloom-forming marine and freshwater algae. Water Research, 73, 216-230.

35. Wong Lopez, E. S. (2019). Tratamiento de aguas de la laguna de Conache-Laredo, para uso en acuicultura, mediante un biofiltro de flujo horizontal.

36. Zárate Sarapura, E. (2021). Modelamiento de curvas de supervivencia no lineal para determinar la inactivación térmica de salmonella ssp., escherichia coli y bacterias ácido lácticas en la carne molida de pollo. 